\title{
The Role of Fetal Neurology in the Progress of Perinatal Medicine
}

\author{
Ritsuko K Pooh*
}

CRIFM Clinical Research Institute of Fetal Medicine PMC, Osaka, Japan

\begin{abstract}
The prevalence of cerebral palsy has not decreased despite major improvements in clinical care in antenatal/ neonatal period as well as intrapartum period. In about $70 \%$ of cases, cerebral palsy results from events occurring before birth that can disrupt normal development of the brain. The antepartum risk factors should include fetal brain mal development and intrauterine brain injuries, which are unclassifiable into congenital brain anomalies and may exist inconspicuously during pregnancy and even after birth. Especially, neuronal migration disorder and acquired brain damage in utero should be responsible for postnatal neurological impairment. Imaging technologies including three dimensional ultrasound have been remarkably improved and contributed to prenatal evaluation of fetal Central Nervous System (CNS) development and assessment of CNS abnormalities in utero. In this article, objective and precise imaging diagnoses of fetal CNS including migration disorders and acquired brain damages. Furthermore, 3D bidirectional power Doppler angiography has depicted fine cerebral vessels of medullary veins which may relate with timing of insult as well as with postnatal neurological prognosis. It is promising to clarify the developmental mechanism of CNS damages with advanced ultrasound diagnostic techniques in the near future. Postnatal unexplained neurological deficits may strongly relate with intrauterine brain development therefore fetal neurology has great responsibility and an important role in perinatal medicine.
\end{abstract}

Keywords: Fetus; Neurology; Congenital; Brain; Vascularity; Ultrasound

\section{Introduction}

In perinatal medicine, one of the most important roles is "to lessen the number of infants with neurological impairment. Cerebral Palsy (CP) is a non-progressive motor disability and its prevalence has remained largely unchanged despite major improvements in clinical care in antenatal/neonatal period as well as intrapartum period. The Surveillance of Cerebral Palsy in Europe (SCPE) reported that the current prevalence of $\mathrm{CP}$ is similar in all six countries in the registry ( 2.12 to 2.45 per 1000 live births) as is the increasing trend in time from well below 2 per 1000 (1.7) live births in the 70's to well above 2 per 1000 live births (2.4) in the 90's [1]. The SCPE also reported that the proportion of low-birth weight infants among all children with CP is rising: $32 \%$ of all cases in 1966 and $50 \%$ in 1989 . It can be very difficult to give an exact reason as to why the brain has been injured or failed to develop. In some instances, there may be no obvious single reason of cerebral palsy. It is generally accepted that causes of cerebral palsy can be multiple and complex. These can include infection in the early part of pregnancy, oxygen deprivation to the brain, abnormal brain development, and restricted intrauterine growth. Furthermore, multiple risk factors such as premature birth, multiple pregnancy, advanced maternal age, low birth weight have been considered.

In about $70 \%$ of cases, cerebral palsy results from events occurring before birth that can disrupt normal development of the brain. Contrary to common belief, lack of oxygen reaching the fetus during labor and delivery contributes to only a small minority of cases of cerebral palsy, according to a 2003 report by the American College of Obstetricians and Gynecologists (ACOG) and the American Academy of Pediatrics (AAP) [2]. They showed a multivariate analysis of 164 cases of neonatal encephalopathy showed $69 \%$ had only antepartum risk factors, $25 \%$ had both antepartum risk factors and evidence for intrapartum hypoxia, $4 \%$ had evidence of intrapartum hypoxia in the absence of preconceptional or antepartum factors that might also have contributed to neonatal encephalopathy and $2 \%$ had no recognized risk factors for neonatal encephalopathy. The antepartum risk factors should include fetal brain maldevelopment and intrauterine brain injuries, which are unclassifiable into congenital brain anomalies and may exist inconspicuously during pregnancy and even after birth.

Imaging technologies have been remarkably improved and contributed to prenatal evaluation of fetal central nervous system (CNS) development and assessment of CNS abnormalities in utero. Introduction of high-frequency transvaginal transducer has contributed to establishing "sonoembryology" [3] and recent general use of transvaginal sonography in early pregnancy enabled early diagnoses of major fetal anomalies [4]. In the middle and late pregnancy, fetal CNS is generally evaluated through maternal abdominal wall. The brain, however, is three-dimensional structure, and should be assessed in basic three planes of sagittal, coronal and axial sections. Sonographic assessment of the fetal brain in the sagittal and coronal sections requires an approach from fetal parietal direction. Transvaginal sonography of the fetal brain opened a new field in medicine, "neurosonography" [5] Transvaginal approach to the normal fetal brain during the second and third trimester was introduced in the beginning of 1990s [6,7]. Transvaginal observation of the fetal brain offers sagittal and coronal views of the brain from fetal parietal direction through the fontanelles and/or the sagittal suture as ultrasound windows [8,9]. Three dimensional (3D) ultrasound combined with transvaginal approach has greatly contributed to neuroimaging diagnoses [10-14]. Fetal 3D neuroimaging has revealed congenital brain anomalies, such as cranium bifidum, holoprosencephaly, agenesis of the corpus callosum, Chiari malformation, and Dandy-Walker complex in a category of primary/ secondary neurulation and procensephalic development [15]. Magnetic

*Corresponding author: Ritsuko K Pooh, CRIFM Clinical Research Institute of Fetal Medicine PMC, 7-3-7, Uehommachi, Tennoji, Osaka City, \#5430001, Osaka, Japan, Tel: +81-6-6775-8111; Fax: +81-6-6775-8122; E-mail: evp-pooh@fetal-medicine-pooh.jp

Received June 12, 2013; Accepted June 25, 2013; Published June 30, 2013

Citation: Pooh RK (2013) The Role of Fetal Neurology in the Progress of Perinatal Medicine. J Health Med Informat S11: 015. doi:10.4172/2157-7420.S11-015

Copyright: @ 2013 Pooh RK. This is an open-access article distributed under the terms of the Creative Commons Attribution License, which permits unrestricted use, distribution, and reproduction in any medium, provided the original author and source are credited. 
resonance imaging is the other great modality to demonstrate fetal CNS during pregnancy $[16,17]$. However, beside congenital anomalies, acquired brain damages caused by hypoxic-ischemic episodes and migration disorders should be responsible for postnatal cerebral palsy. It is a difficult task to provide a precise prediction of subsequent development of cerebral palsy after a given antepartum event or complication. Fetal heart rate monitoring cannot reveal the presence of encephalopathy, and neuroimaging by ultrasound and MR imaging is the most reliable modality for disclosure of silent encephalopathy. In many cases with cerebral palsy with acquired brain insults, especially term-delivered infants with reactive fetal heart rate tracing and good Apgar score at delivery, recent imaging study have confirmed the presence of brain insult in utero, suggesting that the majority of cerebral palsy are of antenpartum rather than intrapartum in origin. Furthermore, mal arrangement of nerve cells, so called migration disorder, with unknown silent causes has not been well clarified even by neuroimaging during fetal period. The author believes that acquired brain insults and migration disorders bears very grave responsibility in cerebral palsy and neurological deficit after birth, and investigation and explication of fetal brain must be the key to the mystery of fetal brain. In this article, the up-to-date fetal neurological evaluation and the future perspectives are described.

\section{Method}

The representative of fetal neurological evaluation is definitely neuroimaging by ultrasound. 3D ultrasound is one of the most attractive modalities in the field of fetal ultrasound imaging. Automatic scan by dedicated 3D transducer produces motor driven automatic sweeping and is called as a fan scan. With this method, shifting and/ or changing angle of the transducer is not required during scanning and scan duration lasts only several seconds. After acquisition of the target organ, multiplanar imaging analysis and tomographic imaging analysis are possible. Combination of both transvaginal high-resolution sonography and 3D ultrasound may be a great diagnostic tool for evaluation of three-dimensional structure of fetal CNS $[18,19]$. Recent advanced 3D ultrasound equipments have several useful functions such as surface anatomy imaging of spinal development, cranial surface and brain surface, bony structural imaging of the calvaria and vertebrae, multiplanar imaging of the intracranial structure, tomographic ultrasound imaging of fetal brain in any cutting section, thick slice imaging of the intracranial structures (Volume contrast imaging, VCI), simultaneous volume contrast imaging of the same section or vertical section of fetal brain structure, volume calculation $[20,21]$ of target organs such as intracranial cavity, ventricle, choroid plexus and intracranial lesions, inversion mode (the cystic portions within the volume are displayed in their entirety as an echogenic area, while the grayscale portions of the image are rendered as transparent [22-24] ) demonstrating hypoechoic parts such as ventricles and cystic lesions, and $3 \mathrm{D}$ power Doppler angiography of the intracranial vascularity $[25,26]$. By utilizing those 3D functions, objective and precise fetal neurological assessment can be done.

\section{Results}

\section{Fetal brain demonstrated by $3 \mathrm{D}$ ultrasound}

In early pregnancy, 3D volume imaging shows surface anatomy of small fetus and intracranial structure in the mid-sagittal section (Figure 1). Obviously different appearance of the brain surface at 19 and 30 weeks of gestation are demonstrated by 3D surface anatomy imaging (Figure 2). Tomographic ultrasound imaging of the brain structure is quite helpful to understand intracranial detailed brain structure (Figure 3).

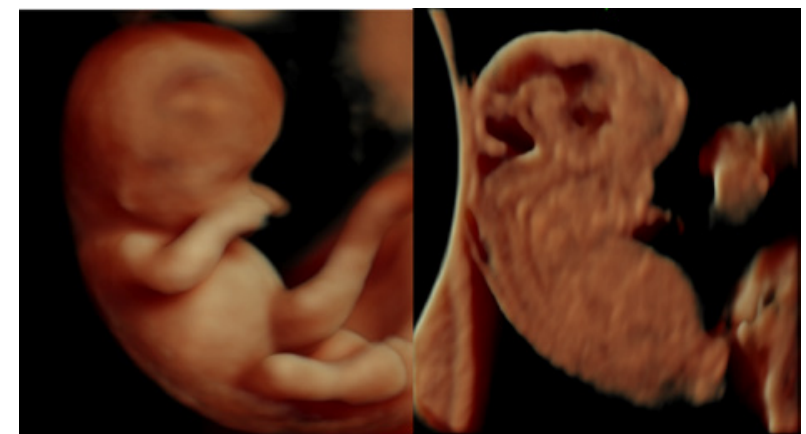

Figure 1: Surface anatomy of small fetus and intracranial structure in the midsagittal section.

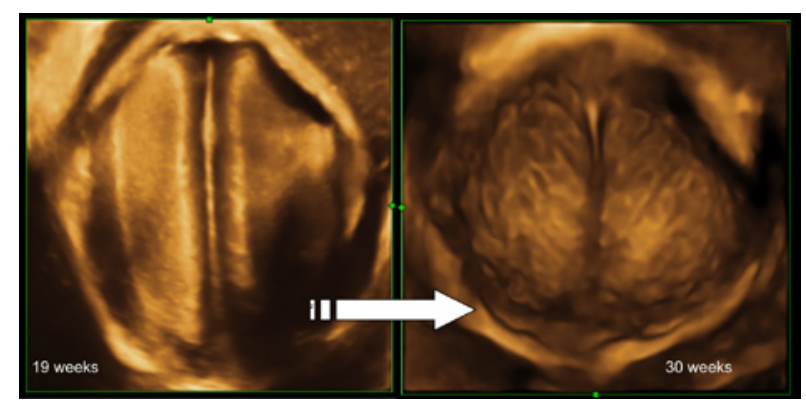

Figure 2: Showing Different appearance of the brain surface at 19 and 30 weeks of gestation by 3D surface anatomy imaging.

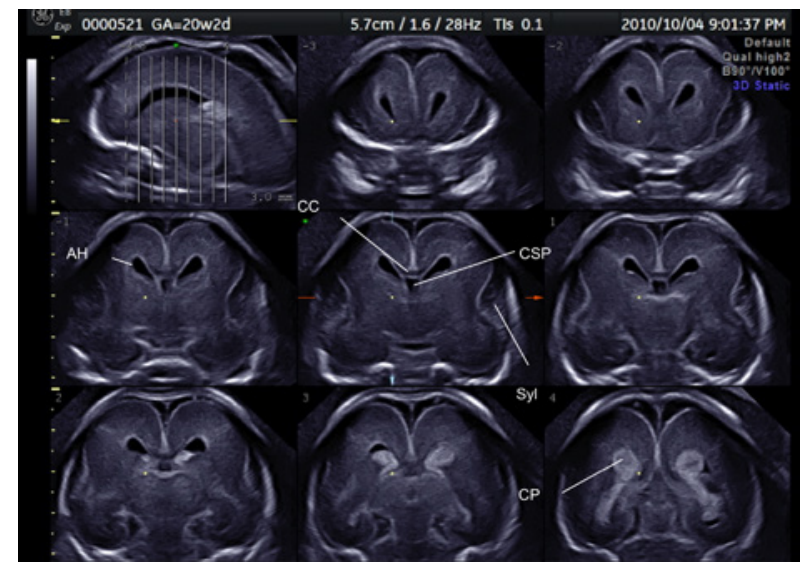

Figure 3: Showing tomographic ultrasound imaging of the brain and detailed brain structure.

TUI demonstrates multi-parallel cutting sections and is quite similar imaging technology to magnetic resonance imaging. The superior point of TUI to MRI is that it is easily possible to change slice width, to rotate the images, to magnify images, and to rotate images to any directions. This function is extremely useful for detailed CNS assessment and also for consultation to neurosurgeons and neurologists. It is possible to compare the anatomy in exactly same cutting section, therefore anatomical brain development is quite comprehensive (Figure 4). Inversion mode is inverted imaging technology which shows volume of only hypoechoic parts. Figure 5 shows TUI and inversion-mode images of enlarged ventricles seen at 19 weeks of gestation. Brain circulation can be well documented during the first trimester. Figure 6 shows the 


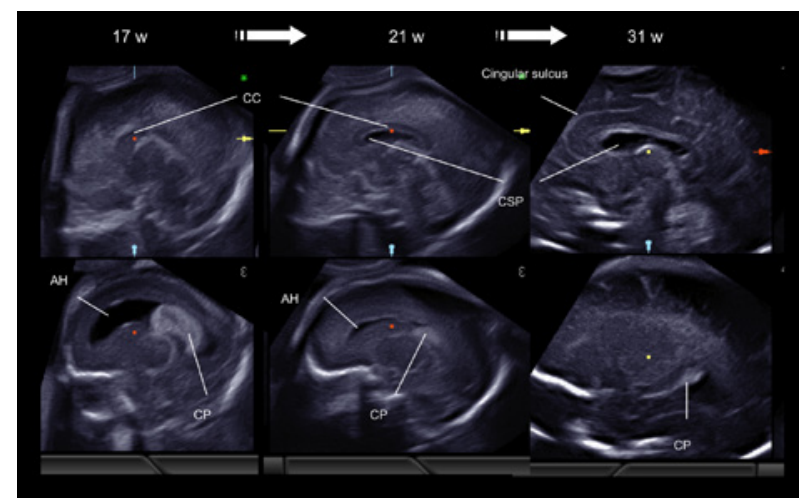

Figure 4: Comparing the anatomy in exactly same cutting section and anatomical brain development.

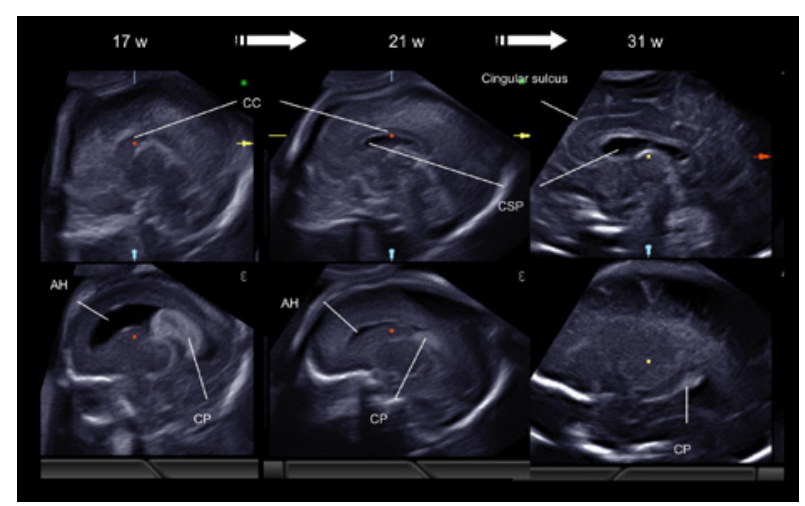

Figure 5: Shows TUl and inversion-mode images of enlarged ventricles seen at 19 weeks of gestation.

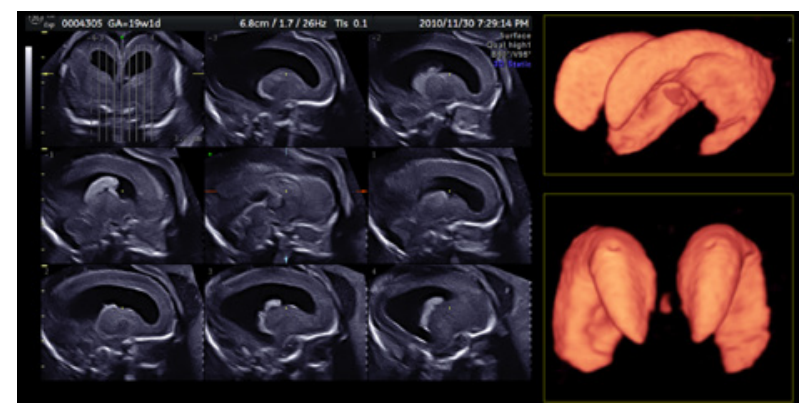

Figure 6: Shows the fetal brain circulation in the axial and sagittal sections at 31 weeks by 3D bidirectional power Doppler.

fetal brain circulation in the axial and sagittal sections at 31weeks by 3D bidirectional power Doppler. Furthermore, recent high-frequent transvaginal neuroscan has been able to demonstrate the medullary vessels from the cortex towards subependymal area. Medullary veins are demonstrated between pial mater and longitudinal vein of Schlesinger in the anterior coronal cutting section and between brain surface and periventricular subependymal area in the parasagittal section [27]. Medullary vessels are detectable from early second trimester and they are rapidly developing during second trimester. Before 20 weeks, medullary veins are demonstrated as red color or red/blue colors by bidirectional power Doppler (Figure 7, left) and thereafter remarkable rapid development is seen into shower-like vessels (Figure 7, right).

\section{Migration disorders}

Abnormal migration of neurons in the developing brain and nervous system causes various brain maldevelopment. Lissencephaly is one of representatives of migration disorders. Figure 8 shows lissencephaly at 30 weeks of gestation with no gyral pattern. Figures 9 and 10, show non-uniformed migration disorder, which resulted in severe neurological prognosis after birth. It has been believed that phenotypes of migration disorders appear in late pregnancy when gyral pattern is visualized. However, the author has experienced some cases with obvious phenotypes of migration disorder from early second trimester. Figure 11 shows maldeveloped brain with migration disorder at 18 weeks of gestation. Prenatal neuroimaging clearly matches the histological findings.

\section{Acquired brain insults}

Acquired brain insults can occur at any gestational age. Figure 12-15 show cases of encephalopathy in various gestations. In Figure 12, early brain hemorrhage with unknown cause may lead to split of brain and intraventricular hemorrhage. Intrauterine encephalopathy can result from various causes, such as vein of Galen aneurysmal malformation

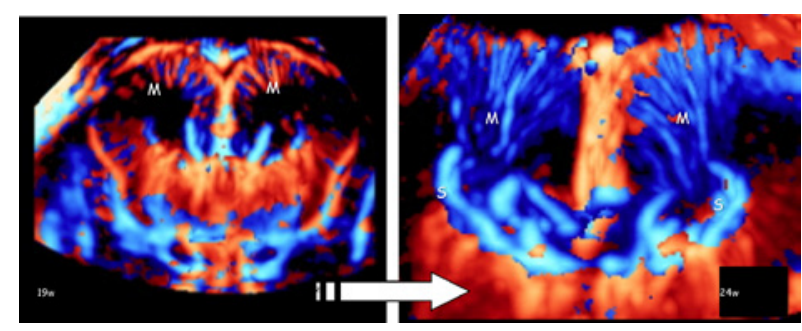

Figure 7: Intracranial vascularity with brain abnormality.

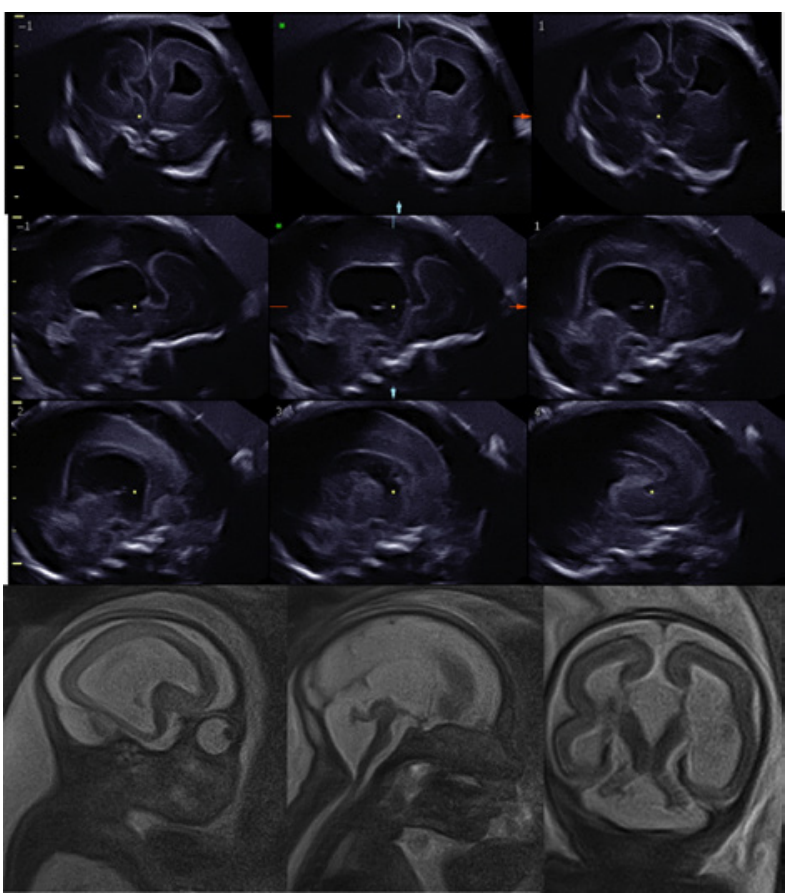

Figure 8: Shows lissencephaly at 30 weeks of gestation with no gyral pattern. 


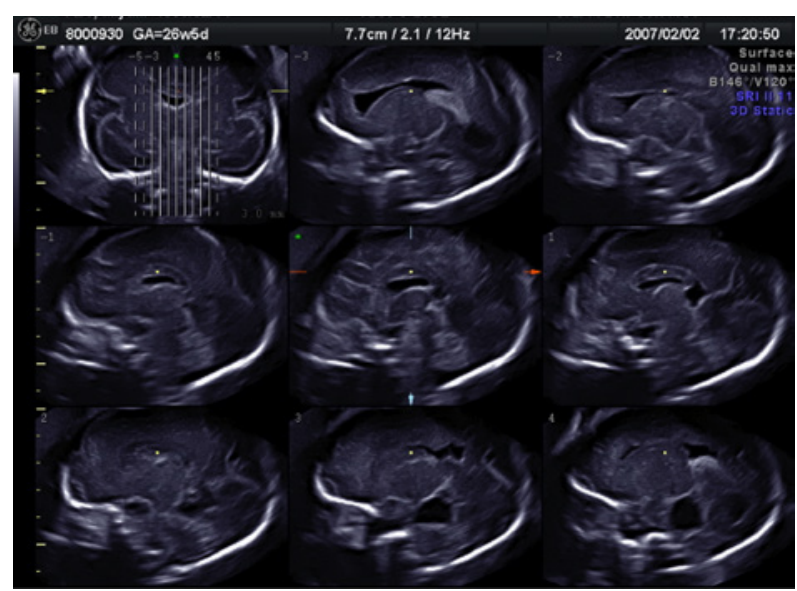

Figure 9: Show non-uniformed migration disorder, which resulted in severe neurological prognosis after birth.

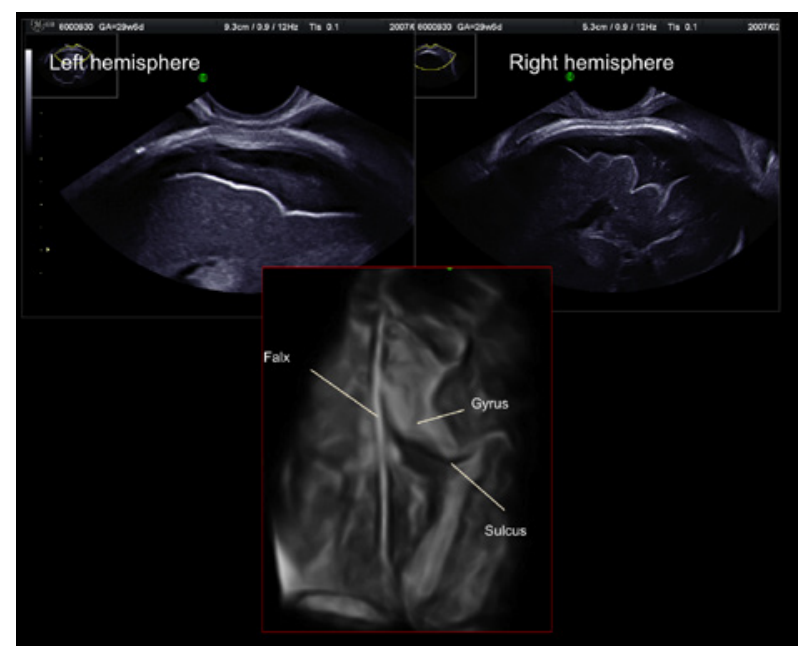

Figure 10: Figure showed non-uniformed migration disorder, which resulted in severe neurological.

(Figure 13), monochorionic twins with one-twin death (Figure 14), high cardiac output due to cardiovascular anomaly (Figure 15) and other causes. Those cases with intrauterine severe encephalopathy resulted in severe cerebral palsy or antenatal/neonatal death.

\section{Intracranial vascularity with brain abnormality}

Medullary veins shown in Figure 7 develop according to brain tissue development. The case shown in Figure 16 was referred at 34 weeks of gestation due to fetal ventriculomegaly with intrauterine growth retardation. Transvaginal TUI with VCI (upper Figure 16) showed multiple intracerebral calcifications with delayed gyral formation and medullary venous maldevelopment with 19-20 week-appearance. Intrauterine cytomegalo viral infection was strongly suspected by neuroimaging despite maternal negative CMV IgM. Amniocentesis resulted in positive CMV-PCR and fetal CMV infection was confirmed. The estimated timing of fetal CMV infection may have been at 1920 weeks or before, because of the appearance of medullary veins. The postnatal neurological prognosis has been poor. Figure 17 shows the case with abnormal brain morphology with normal medullary venous development. Medullary veins appear normal despite obvious ventriculomegaly. The postnatal neurological prognosis has been good for 4 years.

\section{Comments}

Many brain malformations are closely related to neuronal migration disorders [28]. Neuronal migration disorders are caused by the abnormal migration of neurons in the developing brain and nervous system. Neurons must migrate from the areas where they are born to the areas where they will settle into their proper neural circuits. Neuronal migration, which occurs as early as the second month of gestation, is controlled by a complex assortment of chemical guides and signals. When these signals are absent or incorrect, neurons do not end up where they belong. This can result in structurally abnormal or missing areas of the brain in the cerebral hemispheres, cerebellum, brainstem, or hippocampus, including schizencephaly, porencephaly, lissencephaly, agyria, macrogyria, pachygyria, microgyria, micropolygyria, neuronal heterotopias (including band heterotopia), agenesis of the corpus callosum, and agenesis of the cranial nerves.

In terms of encephalopathy or cerebral palsy, 'timing of brain insult, antepartum, intrapartum or postpartum?' is one of the serious

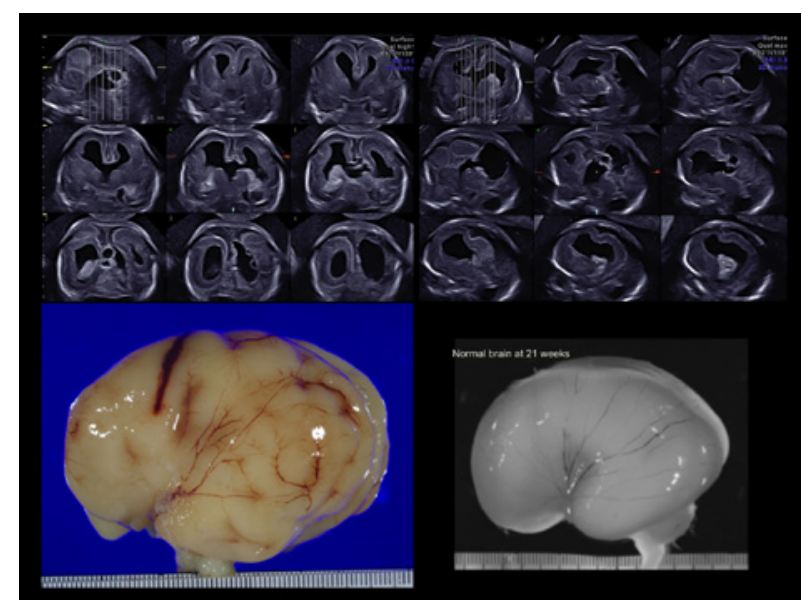

Figure 11: Shows maldeveloped brain with migration disorder at 18 weeks of gestation.

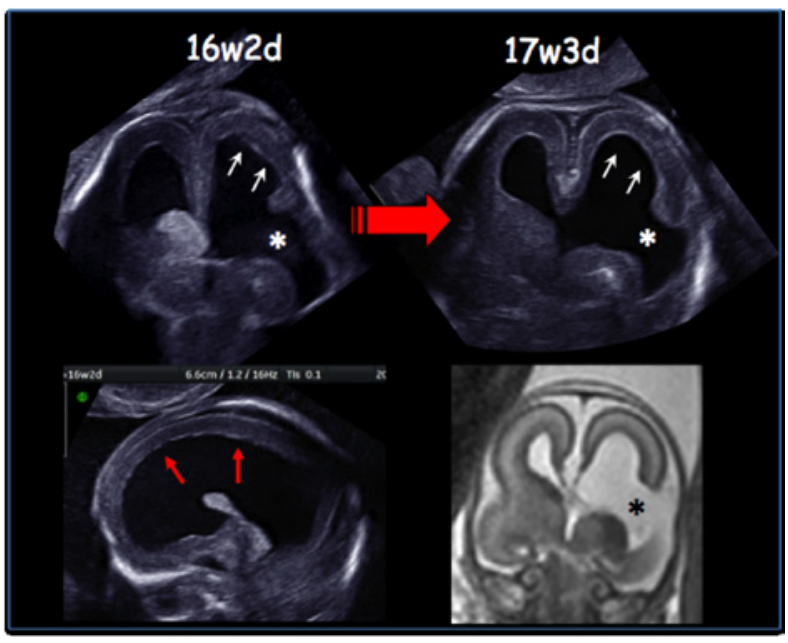

Figure 12: Show cases of encephalopathy in various gestations. 


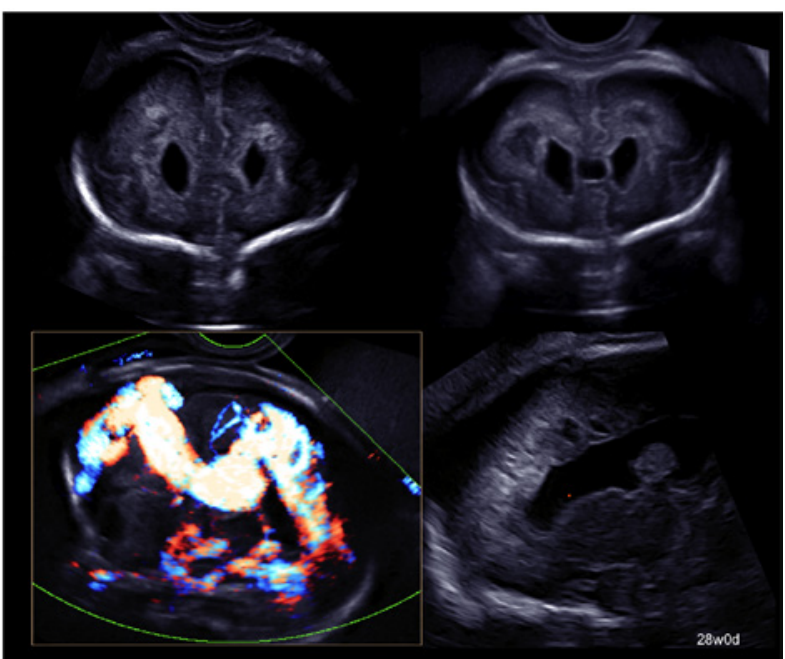

Figure 13: Intrauterine encephalopathy can result from various causes, such as vein of Galen aneurysmal malformation.

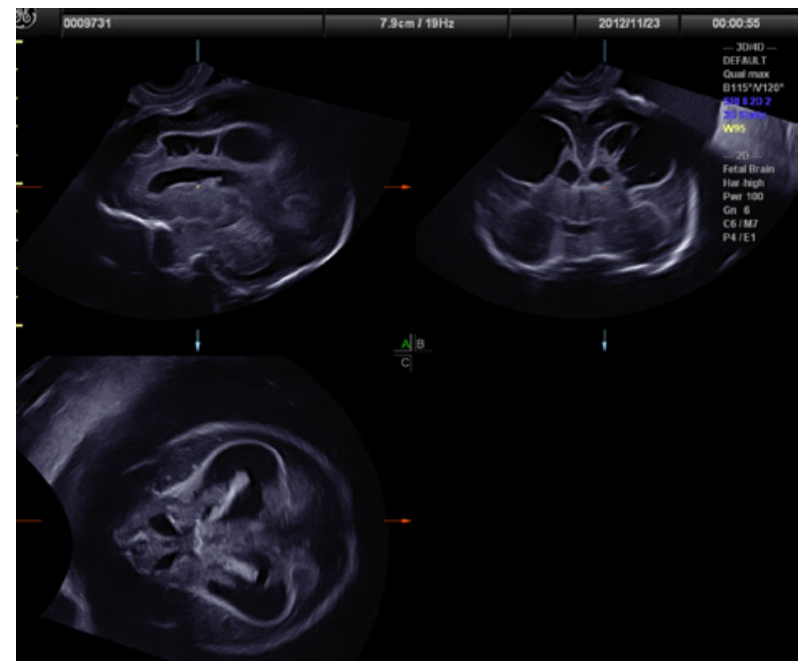

Figure 14: Shows mono chorionic twins with one-twin death.

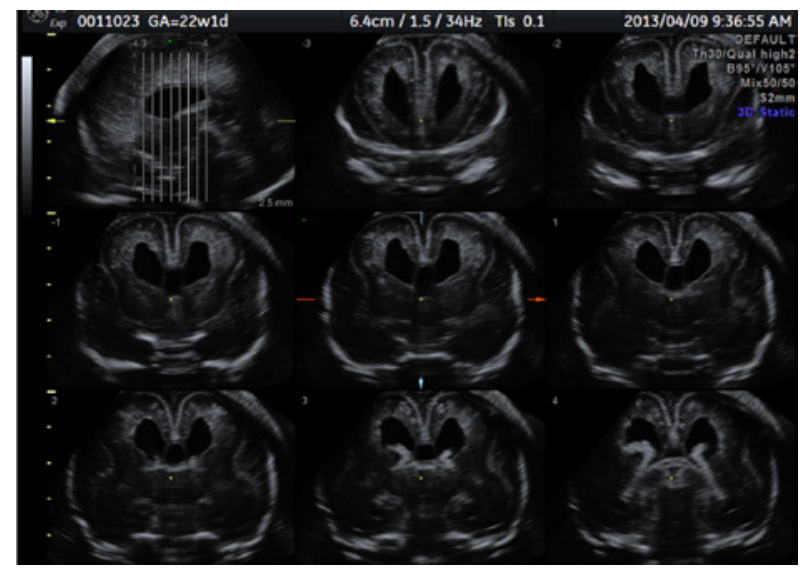

Figure 15: Shows high cardiac output due to cardiovascular anomaly and other causes.

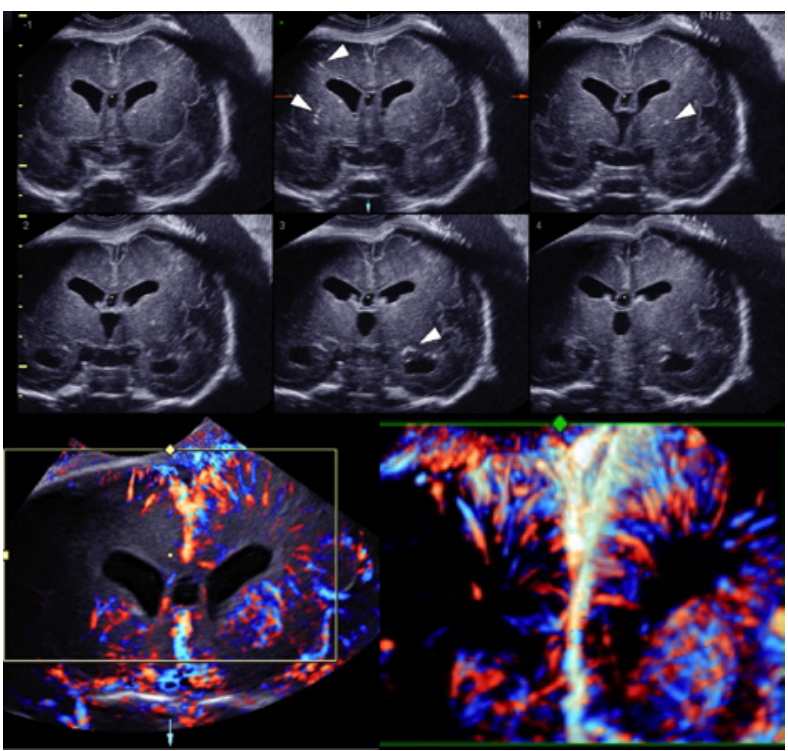

Figure 16: Shows 34 weeks of gestation due to fetal ventriculomegaly with intrauterine growth retardation.

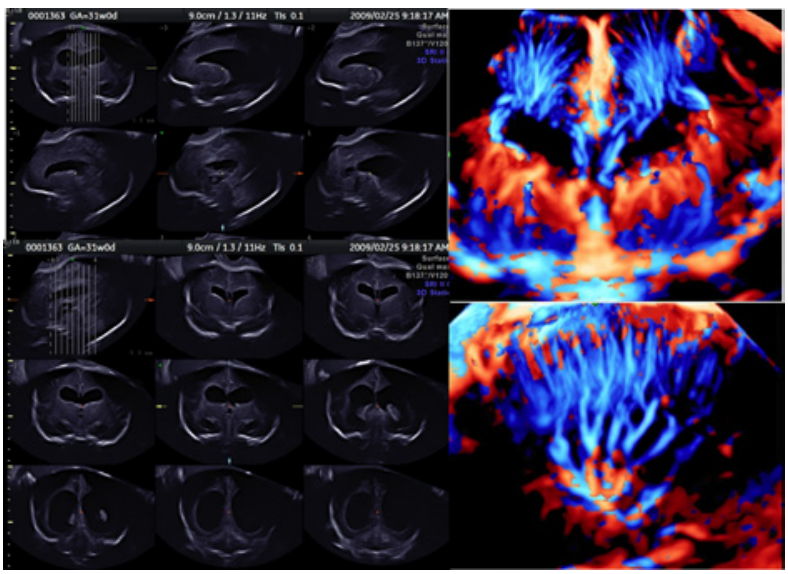

Figure 17: Shows the case with abnormal brain morphology with normal medullary venous development.

controversial issues including medico-socio-legal-ethical problems [15]. Although brain insults may relate to antepartum events in a substantial number of term infants with hypoxic-ischemic encephalopathy, the timing of insult cannot always be certain.

The author first reported brain circulation demonstrated by Transvaginal 2D power Doppler in 1996 [29]. Thereafter, transvaginal $3 \mathrm{D}$ power Doppler assessment of fetal brain vascularity was successful30. Recently, owing to the advanced technology of bidirectional power Doppler, furthermore sophisticated 3D angiostructural image have been able to be demonstrated with vascular direction $[27,30]$. The author first demonstrated the fine medullary veins in 2008, running from the cortex towards the subependymal area by bidirectional power Doppler with 3D angiostructural imaging [31]. In the fetal brain, the medullary veins within the deeper cerebral white matter are more developed than the subcortical veins located within the subcortical white matter [32]. The mall development of medullary veins may indicate brain developmental abnormality, may predict subsequent hydrocephalus, 
and may predict postnatal neurological deficit. The author has been investigating assessment of medullary veins in normal and abnormal brain structure and it is expected that the investigation will lead to one of solutions in the relations between the fetal brain development and postnatal neurological prognosis.

\section{Conclusion}

As described in this article, transvaginal high-resolution ultrasound technology has greatly contributed to fetal neuroscience. It is promising to clarify the developmental mechanism of CNS damages with advanced ultrasound diagnostic techniques in the near future. Neurological prognosis should be longitudinally and carefully evaluated according to precise diagnoses [33]. Considering future development in the field of fetal neurology, those precise morphological detection by transvaginal high-resolution neuroimaging should be combined with four-dimensional ultrasound research on fetal behavior [34-36] and molecular genetics which has recently been remarkably contributed to prenatal diagnosis as Sonogenetics [37,38]. Postnatal unexplained neurological deficits may strongly relate with intrauterine brain development therefore fetal neurology has great responsibility and an important role in perinatal medicine.

\section{References}

1. Odding E, Roebroeck ME, Stam HJ (2006) The epidemiology of cerebral palsy: incidence, impairments and risk factors. Disabil Rehabil 28: 183-191.

2. Hankins GD, Speer M (2003) Defining the pathogenesis and pathophysiology of neonatal encephalopathy and cerebral palsy. Obstet Gynecol 102: 628-636.

3. Timor-Tritsch IE, Peisner DB, Raju S (1990) Sonoembryology: an organoriented approach using a high-frequency vaginal probe. J Clin Ultrasound 18 : 286-298.

4. Pooh RK (1999) B-mode and Doppler studies of the abnormal fetus in the first trimester. In: Chervenak FA, Kurjak A editors. Fetal medicine. Parthenon Publishing, Carnforth 46-51.

5. Timor-Tritsch IE, Monteagudo A (1996) Transvaginal fetal neurosonography: standardization of the planes and sections by anatomic landmarks. Ultrasound Obstet Gynecol 8: 42-47.

6. Monteagudo A, Reuss ML, Timor-Tritsch IE (1991) Imaging the fetal brain in the second and third trimesters using transvaginal sonography. Obstet Gynecol 77: $27-32$

7. Monteagudo A, Timor-Tritsch IE, Moomjy M (1994) In utero detection of ventriculomegaly during the second and third trimesters by transvaginal sonography. Ultrasound Obstet Gynecol 4:193-198.

8. Pooh RK, Nakagawa Y, Nagamachi N, Pooh KH, Maeda K, et al. (1998) Transvaginal sonography of the fetal brain: detection of abnormal morphology and circulation. Croat Med J 39: 147-57

9. Pooh RK, Maeda K, Pooh KH, Kurjak A (1999) Sonographic assessment of the fetal brain morphology. Prenat Neonat Med 4: 18-38.

10. Pooh RK (2000) Three-dimensional ultrasound of the fetal brain. In Kurjak A ed. Clinical application of 3D ultrasonography. Parthenon Publishing, Carnforth 176-180.

11. Pooh RK, Pooh K, Nakagawa Y, Nishida S, Ohno Y (2000) Clinical Application of Three-dimensional Ultrasound in Fetal Brain Assessment. Croat Med J 41: 245-251.

12. Timor-Tritsch IE, Monteagudo A, Mayberry P (2000) Three-dimensional ultrasound evaluation of the fetal brain: the three horn view. Ultrasound Obstet Gynecol 16: 302-306.

13. Monteagudo A, Timor-Tritsch IE, Mayberry P (2000) Three-dimensiona transvaginal neurosonography of the fetal brain: 'navigating' in the volume scan. Ultrasound Obstet Gynecol 16: 307-313.

14. Pooh RK, Pooh KH (2002) Fetal neuroimaging with new technology. Ultrasound Review Obstet Gynecol 2: 178-181.
15. Pooh RK, Maeda K, Pooh KH (2003) An Atlas of Fetal Central Nervous System Disease. Diagnosis and Management. Parthenon CRC Press, London, New York, 2003.

16. Pooh RK, Nagao Y, Pooh KH (2006) Fetal neuroimaging by transvaginal 3D ultrasound and MRI. Ultrasound Rev Obstet Gynecol 6: 123-134.

17. Pooh RK, Kurjak A (2011) 3D and 4D sonography and magnetic resonance in the assessment of normal and abnormal CNS development: alternative or complementary. J Perinat Med 39: 3-13.

18. Pooh RK (2009) Neuroanatomy visualized by 2D and 3D, In Pooh RK, Kurjak A eds Fetal Neurology, Jaypee Brothers Medical Publishers, New Delhi 15-38.

19. Pooh RK, Shiota K, Kurjak A (2011) Imaging of the human embryo with magnetic resonance imaging microscopy and high-resolution transvaginal 3-dimensional sonography: human embryology in the 21st century. Am J Obstet Gynecol 204 77 el-16.

20. Endres LK, Cohen L (2001) Reliability and validity of three-dimensional fetal brain volumes. J Ultrasound Med. 20: 1265-1269.

21. Roelfsema NM, Hop WC, Boito SM, Wladimiroff JW (2004) Three-dimensional sonographic measurement of normal fetal brain volume during the second half of pregnancy. Am J Obstet Gynecol 190: 275-280.

22. Benacerraf BR (2006) Inversion mode display of 3D sonography: applications in obstetric and gynecologic imaging. Am J Roentgenol 187: 965-971.

23. Kusanovic JP, Nien JK, Gonçalves LF, Espinoza J, Lee W, et al. (2008) The use of inversion mode and 3D manual segmentation in volume measurement of fetal fluid-filled structures: comparison with Virtual Organ Computer-aided AnaLysis (VOCAL). Ultrasound Obstet Gynecol 31: 177-186.

24. Hata T, Dai SY, Kanenishi K, Tanaka H (2009) Three-dimensional volumerendered imaging of embryonic brain vesicles using inversion mode. J Obstet Gynaecol Res 35: 258-261.

25. Pooh RK, Pooh K (2001) Transvaginal 3D and Doppler ultrasonography of the fetal brain. Semin Perinatol 25: 38-43.

26. Pooh RK, Pooh KH (2002) The assessment of fetal brain morphology and circulation by transvaginal 3D sonography and power Doppler. J Perinat Med 30: 48-56.

27. Pooh RK, Kurjak A, Tikvica A (2009) Normal and Abnormal Brain Vascularity, In Pooh RK, Kurjak A eds, Fetal Neurology, Jaypee Brothers Medical Publishers, New Delhi 39-58.

28. Ross ME, Walsh CA (2001) Human brain malformations and their lessons for neuronal migration. Annu Rev Neurosci 24: 1041-1070.

29. Pooh RK, Aono T (1996) Transvaginal power Doppler angiography of the fetal brain. Ultrasound Obstet Gynecol 8: 417-421.

30. Pooh RK (1999) Two-dimensional and three-dimensional Doppler angiography in fetal brain circulation. In Kurjak A ed. 3D Power Doppler in Obstetrics and Gynecology. Parthenon Publishing, Carnforth, 105-111.

31. Pooh RK, Pooh KH (2008) Fetal neuroimaging. Fetal and Maternal Medicine Review 19: 1-31.

32. Takashima S, Hirayama A, Okoshi Y, Itoh M (2002) Vascular, Axonal and Glial Pathogenesis of Periventricular Leukomalacia in Fetuses and Neonates Neuroembryology 1:72-77

33. Pooh RK (2012) Imaging diagnosis of congenital brain anomalies and injuries. Semin Fetal Neonatal Med 17: 360-376

34. Amiel-Tison C, Gosselin J, Kurjak A (2006) Neurosonography in the second half of fetal life: a neonatologist's point of view. J Perinat Med 34: 437-46.

35. Kurjak A, Tikvica A, Stanojevic M, Miskovic B, Ahmed B, et al. (2008) The assessment of fetal neurobehavior by three-dimensional and four-dimensional ultrasound. J Matern Fetal Neonatal Med 21: 675-684.

36. Kurjak A, Abo-Yaqoub S, Stanojevic M, Yigiter AB, Vasilj O, et al. (2010) The potential of 4D sonography in the assessment of fetal neurobehaviormulticentric study in high-risk pregnancies. J Perinat Med 38: 77-82.

37. Pooh RK, Choy KW, Leung TY, Lau TK (2011) Sonogenetics -A breakthrough in prenatal diagnosis-. Donald School Journal of Ultrasound in Obstetrics and Gynecology 5: 75-79

38. Pooh RK (2012) Sonogenetics in fetal neurology. Semin Fetal Neonatal Med 17: 353-359. 